\title{
Cosmetic labiaplasty on minors: a review of current trends and evidence
}

\author{
Andreas Kalampalikis $\mathbb{D}^{1 凶}$ and Lina Michala ${ }^{1}$ \\ (c) The Author(s), under exclusive licence to Springer Nature Limited 2021
}

Cosmetic labiaplasty is a form of Female Genital Cosmetic Surgery (FGCS) that is performed with the deliberate intent to alter the appearance and morphology of the external genitalia in the absence of medical concerns. Over the last decade, there is an increasing demand for FGCS and the industry behind it is constantly growing. Adolescents comprise an extremely vulnerable population, with labiaplasties in this particular age group having also increased. However, labiaplasty has been widely contested due to the irrevocable alteration of a psychosexually significant body part on minors too young to consent. Besides, the changes that occur during pubertal development in the genital area can significantly alter pediatric surgical results. Genital anatomy is more diverse than we previously thought and there is evidence to suggest that the labia minora with their rich innervation play an important role in sexual arousal and pleasure. Education regarding the wide range of normal genital appearance suffices in most cases to dissolve concerns regarding body self-image. Mental health issues should always be explored and, if identified, the girl should be referred to an experienced professional for their resolution. Postponing labiaplasty until adulthood is strongly recommended to help adolescents achieve a well-informed decision regarding an irreversible procedure with possible adverse esthetic and functional outcomes.

IJIR: Your Sexual Medicine Journal; https://doi.org/10.1038/s41443-021-00480-1

\section{BACKGROUND}

Female genital cosmetic surgery (FGCS) is an umbrella term that refers to legal procedures performed with the deliberate intent to alter the appearance of the genital area in the absence of clear physical or functional medical necessity. It includes various types of operations, such as labiaplasty, clitoral hood reduction, perineoplasty (tightening of the vaginal opening), vaginoplasty, hymenoplasty, vulval lipoplasty, and G-spot augmentation [1, 2].

Contemporary pubic grooming trends affect considerably how women perceive and treat their genitals. Practices such as pubic hair removal, through shaving, plucking, or permanent laser treatment, have drawn attention to a sensitive area that was previously hidden [2]. Tight-fitting clothes and poorly-fitting undergarments make the genital area more visible. At the same time, the vulva is typically represented in the mass media as hairless and flat with no protrusion beyond the labia majora, similar to a prepubescent esthetic $[2,3]$.

The internet is an important source of information. Adolescents in an attempt to explore their body and sexuality use cyberspace as an educational resource often without supervision. They are inevitably exposed to explicit material either by chance or by choice [4]. The increasing depictions of hairless genitalia with no visible labia minora in pornographic magazines and websites, create a distorted view of what is normal and fail to represent the true diversity of the human body [4,5]. This biased perception, in combination with the aggressive marketing of plastic surgeons and the increasing acceptance of cosmetic surgery, has possibly contributed to the recent, growing demand for FGCS [5].
In many instances, FGCS providers deploy terms like "labial hypertrophy", as if it were a recognizable and clearly defined condition, in order to confer "treatment" status in labiaplasty. For labial hypertrophy to attain disease status, normality in measurement and function would need to be defined. This work has simply not been done. Currently, labial hypertrophy is neither definable nor measurable [6]. One person's hypertrophy could be another's normality.

\section{LABIAL ANATOMY}

There is wide variation in the anatomy of the female genital area. The external genitalia undergo a significant transformation during pubertal development, which is when changes in the appearance and the prominence of the labia majora and minora arise and continue until full maturity is achieved. Similar changes occur also in adulthood, particularly during pregnancy and childbirth and after menopause [7]. Several erogenous areas have been described in the female genitalia. These include the clitoris, the labia minora, the clitoral hood [8], and the so-called Gräfenberg spot or G-spot (evidence for which is contested) [9]. However, greater sexual pleasure is typically derived from the stimulation of the labia minora than from the labia majora, a finding that indicates a denser innervation to this area. Interestingly, women with self-reported larger labia majora and minora derive more sexual pleasure from the stimulation of these areas than women who perceive their labia to be smaller, possibly owing to the greater surface of contact [8].

\footnotetext{
${ }^{1}$ 1st Department of Obstetrics and Gynecology, National and Kapodistrian University of Athens, Athens, Greece. ${ }^{凶}$ email: andreas.kal@hotmail.com
} 
The structure, function, and appearance of the vulva are poorly covered in the medical literature. Descriptions and depictions of the female external genitalia in anatomy and gynecology textbooks are kept to a minimum, giving the impression that there is minimal variation in the appearance of the clitoris, prepuce, and labia. Often the same descriptive diagram is duplicated from one textbook to another resulting in generations of medical students with limited exposure to the true diversity of female genital anatomy [10]. Additionally, despite the detailed descriptions of pubertal changes of the breast and pubic hair by Marshall and Tanner, labial anatomy changes have not been categorized to date [11].

However, over the past 15 years, there have been attempts to describe in more detail the female external genitalia, suggesting a wide variation in the appearance of the vulva, clitoris, labia majora and minora, both in adults and adolescents $[12,13]$. Different studies have tried to objectively measure the dimensions of the labia minora, with the width of the labium minus ranging from 1 to $62 \mathrm{~mm}$ and its length from 5 to $100 \mathrm{~mm}$. Asymmetry between the left and right labium is also quite frequent [12-14].

\section{TYPES OF SURGICAL PROCEDURES AND UPTAKE}

There are different types of labiaplasty and, to date, eight different labiaplasty approaches have been described. These include composite reduction labiaplasty, wedge resection, de-epithelialization, edge resection or labial trimming, laser labiaplasty, custom flask labiaplasty, W-shaped resection, and fenestration labiaplasty with inferior flap transposition. The type of surgical approach depends on the size of the labia minora and the operation goals, in other words on how much tissue the girl or woman wishes to have removed. Different surgical approaches claim to achieve better esthetic results, less scarring, better contour, and less color discordance of the connected tissues post-surgery, while refined techniques are often promoted as improvements to previous methods [15]. Nevertheless, double-blinded studies are not available and the type of surgery performed usually falls under the surgeon's preference.

Despite the evolution in surgical techniques, complications continue to occur in about 1 in 15 cases, however, they are minor and usually resolve without further treatment. Revision surgery, due to healing complications or postoperative bleeding, has been reported in up to $4.1 \%$ of the cases. The rate of reoperation with secondary resection differs between studies but can be as high as 7\% [15].

The American Esthetic Plastic Surgery National Databank reveals that, despite the restrictions due to the COVID-19 pandemic, during 2020, the total revenue for cosmetic surgery was over 9 billion U.S. dollars. At the same time, 13,697 labiaplasties were performed [16]. This number demonstrates an increase when compared with 12,903 and 9945 labiaplasties performed in 2019 and 2015, respectively. Interestingly, there were no labiaplasties performed in women under the age of 17 recorded in 2019, possibly indicating a shift in practice after the release of relevant guidelines and ethical opinions by various professional bodies [17]. Worldwide, the number of labiaplasties performed in 2019 reached 164,667 , which corresponded to a $24.1 \%$ increase compared to 2018 and a $73.3 \%$ rise compared to 2015 . Labiaplasty was the 15th most popular plastic surgery procedure among female patients for 2019 [18]. However, since reporting for procedures performed in the private sector is not mandatory, these figures may underestimate the true proportions.

\section{OUTCOMES OF STUDIES THAT INCLUDE ADOLESCENTS}

An early report of labiaplasty outcomes was conducted by Rouzier et al. [19], referring to patients aged 12-67 years, who underwent inferior wedge resection. According to this retrospective study, 11 patients $(7 \%)$ required reoperation due to would-dehiscence. Overall, $89 \%$ of the patients were satisfied with the esthetic result of the operation and $93 \%$ with the functional outcome, according to the providers. However, 4 patients (4\%) would not undergo the procedure again if they were given a second chance [19]. Pardo et al. studied a group of 55 women aged 10-55 years for 2 months after laser labiaplasty and reported a high satisfaction rate of $100 \%$ and only minimal suture dehiscence in 3 patients that did not require intervention [20]. Alter et al. reported on the outcomes of 407 women undergoing extended central wedge resection labiaplasty aged 13-63 years, of which 35 were $13-19$ years old. The number of severe complications was 18 (4.4\%), with 12 patients $(2.9 \%)$ requiring reoperation. Out of the 166 patients, who completed a satisfaction questionnaire, two were unsure of whether they would undergo the surgery again and one would choose not to do the operation if she was given a second opportunity. Nine patients reported a negative change in sensation, with five having difficulty in reaching orgasm and four complaining of decreased sensitivity. In three patients there was an increase in discomfort post-operatively. However, the fact that no pre-operative assessment was performed limits the significance of these findings [21].

Solanki et al. retrospectively reviewed the medical records of 12 patients, who underwent W-shaped resection. Two of the patients were minors and had no reported complications. The satisfaction rate, claimed by the providers, was high, however, the study failed to comment on whether an assessment tool was used for that purpose [22]. Trichot et al. in 2011 reported on the outcomes of 21 women undergoing labiaplasty, 5 of them being underaged. There were three patients (14\%) with a partial splitting of the healing scar, one of whom required revision surgery. A questionnaire was filled by 18 patients, all reporting satisfaction with the outcome. There was one patient not satisfied with the esthetic outcome, but who reported symptom improvement [23]. The aforementioned studies include adolescents and adults as well, therefore, we are not sure how far these results apply to the minors in the cohorts.

Jothilakshmi et al. reviewed the notes of six adolescents (age range 11-16) undergoing labiaplasty. Three were operated on for esthetic reasons and three for physical complaints. No complications were noted at the 6-week follow-up visit. The providers reported that all patients were satisfied with the outcome, however, no validated questionnaire was used to assess that [24]. Recently, another study was published referring exclusively to the adolescent population. Patients that had been subjected to labiaplasty were retrospectively approached and were asked to fill in validated questionnaires regarding their sexual function and genital self-image. According to the study, there was a complication rate of $20.5 \%$ (including $14 \%$ wound dehiscence, $9.3 \%$ significant bleeding, 1 wound infection) and a reoperation rate of $6.8 \%$. Out of the 44 subjects, only 28 could be reached and, of them, only 17 completed the questionnaires. Despite poor followup and high complication rates, the providers reported that $47 \%$ of the participants were fully and $53 \%$ partially satisfied with the outcome of the procedure. Also of note, $75 \%$ of participants met the cut-off criteria for "Hypoactive Sexual Desire Disorder (HSDD)" [25]. The retrospective design, poor response rate, small numbers, and the contested diagnosis of $\operatorname{HSDD}[26,27]$ raise questions about the value of this research.

Finally, there is a case report of a 10-year-old patient operated on for left labial asymmetry with edge resection. Nine months later the patient presented with right labial asymmetry and underwent re-operation with trimming of her right labium to match the other side [28]. This kind of observation emphasizes the need for research regarding female genital pubertal development and stresses the importance to postpone any intervention to at least past the age of genital maturation.

Several other studies evaluate the outcomes of FGCS in women, nonetheless, with a smaller sample size or focusing on the adult 
population. What is interesting in the studies reviewed above is the low response rate. Liao and Creighton suggest that postoperatively, women wish to regard their genital area as a natural part of their body and not as an artificial construction that is foreign to them. Hence, most patients, either satisfied or dissatisfied, will probably abstain from any relevant research. Additionally, most of the research reports fail to mention the dropout rates; however, those that do, suggest that this rate can be as high as $50 \%[1,29]$. Most of the studies inquiring about patient satisfaction after FGCS utilize "ad hoc" instruments (i.e., that have not been formally developed and tested), with few of them using validated questionnaires. Even though some of the validated tools can be used for labiaplasty patients, they are not specific for FGCS, hence caution is needed when conclusions about the benefits of such procedures are made [30]. Despite the positive outcomes reported, findings cannot be generalized and more rigorous research is required.

\section{PROFESSIONAL PERSPECTIVES}

In a study performed in Australia, General Practitioners (GPs) were asked regarding their knowledge and attitude towards FGCS. A questionnaire was sent via email to approximately $11,000 \mathrm{GPs}$. The overall response rate was $4 \%$. There were 443 answers, corresponding to $1 \%$ of Australian GPs. The majority (74\%) were female, probably indicating an increased interest on their behalf on the subject of genital cosmetic surgery. Interestingly, 35\% of the GPs had examined patients under the age of 18 requesting FGCS, with the youngest patient being 10 years old. A striking $75 \%$ felt that their knowledge on the subject was inadequate, whereas only a small proportion of the respondents felt that they were confident discussing with the patients the long-term (24\%) and short-term (34\%) risks of the procedure. More than half of the GPs believed that FGCS should not be performed in minors unless there are "genuine medical reasons", implying that almost half of them (i.e., the remaining proportion of the respondents) deem labiaplasty in minors ethical even for merely cosmetic reasons [31]. The low response rate decreases the generalizability of these findings since it may introduce response bias to the study. There is also a high chance that such trends exist also among other specialties that care for young patients.

In another study, performed in the Netherlands, physicians from different specialties, 80 plastic surgeons, 43 gynecologists, and 41 GPs, were asked about their opinion on different clinical cases and whether they were willing or not to perform or refer these patients to FGCS. Plastic surgeons demonstrated a low threshold for offering cosmetic surgery to patients and were more likely to favor small labia compared to gynecologists and GPs. Male physicians were also more likely to perform or refer to surgery, compared to their female counterparts. 95\% of the GPs showed an understanding attitude towards women requesting FGCS. Overall, $65 \%$ were prepared to refer women to surgery, whereas only one-third would do so only in the presence of physical complaints. Participants were also shown a picture of a patient, who had already undergone labial reduction, and were asked whether they would refer this woman to labiaplasty. Oddly, half of the plastic surgeons and a fifth of the gynecologists would still perform a labiaplasty upon request [32].

To resolve these issues the Royal College of Obstetricians and Gynecologists (RCOG) released in 2013 an ethical opinion paper regarding the practice of FGCS. It states that women seeking FGCS should be informed about the wide variations of normal genital anatomy. This act alone can reassure most women and dissolve any insecurities concerning their genital appearance. Adolescents and young women seeking FGCS should be evaluated for any underlying psychological problems, such as Body Dysmorphic Disorder (BDD), and offered the opportunity for a psychological evaluation by a trained professional. They should be informed about the risks of the operation, along with the lack of robust evidence about its positive effects. More importantly, since genital development has not been completed until adulthood, it is "desirable" that FGCS should be performed only over the age of 18 [33].

The American College of Obstetricians and Gynecologists (ACOG) is in line with these recommendations and states additionally that labiaplasty should only be performed in minors with significant congenital malformations or persistent symptoms that the physician believes are caused directly by labial anatomy or both [34]. The Society of Obstetricians and Gynecologists of Canada (SOGC) further states that there is little evidence to support that FGCS improves sexual satisfaction and self-image and the data on the long-term outcomes of these procedures are incomplete. Any possibility of exploitation or coercion should be excluded. Physicians that treat adolescents requesting FGCS should have an additional level of expertise in consulting minors. However, these procedures should not be offered until full maturity has been reached, including genital maturity and legal age of consent. The SOCG proposes the age of 16 as the minimum threshold, after which FGCS could be considered [7].

The British Society for Pediatric and Adolescent Gynecology (BritSPAG) in its position statement, which was released in 2013, raises the issue of poor cosmetic outcomes or structural problems that may ensue after a labiaplasty performed before complete pubertal development. These risks, along with the risk of reoperation, should be clearly communicated to the candidates of FGCS. Alternatively, simple measures (avoidance of harsh soaps and shower gels, use of emollient agents, and comfortable underwear) should be proposed to alleviate symptoms and, if necessary, referral to a specialist for psychological assessment [35].

The Royal Australian College of General Practitioners (RACGP) has issued a resource for GPs regarding the management of women requesting FGCS. This guide emphasizes how diverse the appearance of the vulva is and how GPs can contribute to decreasing anxiety regarding body self-image, by educating the patients about the naturally diverse genital anatomy. Doctors are encouraged to explore the issues behind a request for FGCS and, should mental health or relationship issues arise, they should refer accordingly. Taking into account that gynecologists have a more in-depth knowledge of the female anatomy, a second opinion is advisable, however, this should be clearly stated in the referral note. Labiaplasty in adolescents is discouraged since complete genital development has not been achieved until the age of 18 [2].

The notion that women's concerns regarding their genital appearance can resolve through reassurance and education only is supported by a Dutch study performed by Laan et al. In this experiment, participants were either shown pictures of unmodified vulvas or pictures of neutral objects. The group of women that were exposed to vulvar pictures demonstrated an improvement in genital self-image compared to the control group. This improvement was still maintained 2 weeks after the experiment [36]. On the other hand, the practice of not offering labiaplasty to women with BDD has been recently contested. The reason behind that stems from the idea that denying such an intervention to these patients might reinforce the person's preoccupation with their genital area, whereas the operation itself can result in immediate relief, in the same way that pinnaplasty and breast reduction offer immediate and unambiguous satisfaction [37].

The practice of labiaplasty on minors is characterized by a poor understanding of genital concerns and distress. Besides, highquality research about long-term health and harm of labiaplasty along physical, psychological, and sexual dimensions is absent. Operating on minors, unable to give consent, causing an irrevocable alteration on healthy and psychosexually significant body parts, remains to date highly controversial and is a topic for serious ethical debate. 


\section{CONCLUSION}

Labiaplasty is a procedure with unknown benefits and known harms and the evidence on the long-term outcomes of the procedure are still of insufficient quality. Adolescents comprise an extremely vulnerable population, mainly because they lack the proper knowledge and maturity to reach a well-informed decision regarding an irrevocable alteration to their bodies. Nevertheless, their concerns should not be disregarded and all issues about their request should be discussed thoroughly. Nuanced education about the natural diversity of the vulval anatomy is an important starting point to address genital body image anxiety. Referral to a psychologist is justified, especially if there are pertinent mental health factors. Labiaplasty could be considered in patients with persistent physical symptoms that do not resolve with conservative measures; nonetheless, it should be made clear that surgery may not improve symptoms, is not without risks, and data on the long-term outcomes are still missing. Safeguarding the well-being of adolescents is our obligation, both legal and moral, and supporting them in such an important aspect of their sexual health should be our priority.

\section{REFERENCES}

1. Liao LM, Creighton SM. Female genital cosmetic surgery: solution in pursuit of a problem. In: Creighton SM, Liao LM, editors. Female genital cosmetic surgery: solution to what problem? Cambridge: Cambridge University Press; 2019.

2. The Royal Australian College of General Practitioners (RACPG). Female genital cosmetic surgery. A resource for general practitioners and other health professionals. Melbourne: The Royal Australian College of General Practitioners; 2015.

3. Bramwell R. Invisible labia: the representation of female external genitals in women's magazines. Sex Relat Ther. 2010;17:187-90.

4. Michala L. The adolescent and genital dissatisfaction. Clin Obstet Gynecol. 2020;63:528-35.

5. Howarth C, Hayes J, Simonis M, Temple-Smith M. 'Everything's neatly tucked away': young women's views on desirable vulval anatomy. Cult Health Sex. 2016;18:1363-78.

6. Clerico C, Lari A, Mojallal A, Boucher F. Anatomy and aesthetics of the Labia Minora: The Ideal Vulva? Aesthetic Plast Surg. 2017;41:714-9.

7. Shaw D, Lefebvre G, Bouchard C, Shapiro J, Blake J, Allen L, et al. Female genital cosmetic surgery. J Obstet Gynaecol Can. 2013;35:1108-12.

8. Schober JM, Alguacil NM, Cooper RS, Pfaff DW, Meyer-Bahlburg HFL. Selfassessment of anatomy, sexual sensitivity, and function of the labia and vagina. Clin Anat. 2015;28:355-62.

9. Vieira-Baptista P, Lima-Silva J, Preti M, Xavier J, Vendeira P, Stockdale CK. G-spot: fact or fiction?: a systematic review. Sex Med. 2021;9:100435.

10. Andrikopoulou M, Michala L, Creighton SM, Liao LM. The normal vulva in medical textbooks. J Obstet Gynaecol. 2013;33:648-50.

11. Michala L, Koliantzaki S, Antsaklis A. Protruding labia minora: abnormal or just uncool? J Psychosom Obstet Gynecol. 2011;32:154-6.

12. Lloyd J, Crouch NS, Minto CL, Liao LM, Creighton SM. Female genital appearance: 'normality' unfolds. BJOG. 2005;112:643-6.

13. Brodie K, Alaniz V, Buyers E, Caldwell B, Grantham E, Sheeder J, et al. A study of adolescent female genitalia: What is Normal? J Pediatr Adolesc Gynecol. 2019;32:27-31.

14. Kreklau A, Vâz I, Oehme F, Strub F, Brechbühl R, Christmann C, et al. Measurements of a 'normal vulva' in women aged 15-84: a cross-sectional prospective single-centre study. BJOG 2018;125:1656-61.

15. Oranges CM, Sisti A, Sisti G. Labia Minora reduction techniques: a comprehensive literature review. Aesthet Surg J. 2015;35:419-31.

16. The Aesthetic Society. Aesthetic Plastic Surgery National Databank Statistics 2020. https://cdn.surgery.org/media/statistics/aestheticplasticsurgerynationaldatabank2020stats.pdf. Accessed Jul 2021

17. The Aesthetic Society. Aesthetic Plastic Surgery National Databank Statistics 2019. https://www.surgery.org/sites/default/files/Aesthetic-Society_Stats2019Book_ FINAL.pdf. Accessed Jul 2021.

18. International Society of Aesthetic Plastic Surgery. International Survey on Aesthetic/Cosmetic Procedures performed in 2019. https://www.isaps.org/wpcontent/uploads/2020/12/Global-Survey-2019.pdf. Accessed Jul 2021.
19. Rouzier R, Louis-Sylvestre C, Paniel BJ, Haddad B. Hypertrophy of labia minora: experience with 163 reductions. Am J Obstet Gynecol. 2000;182:35-40.

20. Pardo J, Solà V, Ricci P, Guilloff E. Laser labioplasty of Labia Minora. Int J Gynaecol Obstet. 2006;93:38-43.

21. Alter GJ. Aesthetic Labia Minora and Clitoral Hood reduction using extended central wedge resection. Plast Reconstr Surg. 2008;122:1780-9.

22. Solanki NS, Tejero-Trujeque R, Stevens-King A, Malata CM. Aesthetic and functional reduction of the labia minora using the Maas and Hage technique. J Plast Reconstr Aesthet Surg. 2010;63:1181-5.

23. Trichot $C$, Thubert $T$, Faivre $E$, Fernandez $H$, Deffieux $X$. Surgical reduction of hypertrophy of the labia minora. Int J Gynaecol Obstet. 2011;115:40-3.

24. Jothilakshmi PK, Salvi NR, Hayden BE, Bose-Haider B. Labial reduction in adolescent population-a case series study. J Pediatr Adolesc Gynecol. 2009;22:53-5.

25. Jodoin A, Dubuc E. Labia Minora surgery in the adolescent population: a crosssectional satisfaction study. J Sex Med. 2021;18:623-31.

26. Chańska W, Grunt-Mejer K. The unethical use of ethical rhetoric: the case of flibanserin and pharmacologisation of female sexual desire. J Med Ethics. 2016;42:701-4.

27. Meixel A, Yanchar E, Fugh-Berman A. Hypoactive sexual desire disorder: inventing a disease to sell low libido. J Med Ethics. 2015;41:859-62.

28. Lynch A, Marulaiah M, Samarakkody U. Reduction labioplasty in adolescents. J Pediatr Adolesc Gynecol. 2008;21:147-9.

29. Veale D, Naismith I, Eshkevari E, Ellison N, Costa A, Robinson D, et al. Psychosexual outcome after labiaplasty: a prospective case-comparison study. Int Urogynecol J. 2014;25:831-9.

30. Sharp G, Maynard P, Hamori CA, Oates J, Sarwer DB, Kulkarni J. Measuring quality of life in female genital cosmetic procedure patients: a systematic review of patient-reported outcome measures. Aesthet Surg J. 2020;40:311-8.

31. Simonis $M$, Manocha $R$, Ong JJ. Female genital cosmetic surgery: a cross-sectional survey exploring knowledge, attitude and practice of general practitioners. BMJ Open. 2016;6:e013010.

32. Reitsma W, Mourits MJE, Koning M, Pascal A, van der Lei B. No (Wo)Man is an Island-the influence of Physicians' personal predisposition to Labia Minora appearance on their clinical decision making: a cross-sectional survey. J Sex Med. 2011;8:2377-85.

33. Royal College of Obstetricians and Gynaecologists. Ethical opinion paper. Ethical considerations in relation to female genital cosmetic surgery (FGCS). London: RCOG; 2013.

34. American College of Obstetricians and Gynecologists' Committee on Gynecologic Practice. Elective female genital cosmetic surgery: ACOG Committee Opinion, number 795. Obstet Gynecol. 2020;135:e36-e42.

35. British Society for Paediatric and Adolescent Gynaecology (BritSPAG). Position Statement: Labial Reduction Surgery (Labiaplasty) on Adolescents. https://www. rcog.org.uk/globalassets/documents/news/britspag_labiaplastypositionstate ment.pdf. Accessed Jul 2021.

36. Laan E, Martoredjo DK, Hesselink S, Snijders N, van Lunsen RHW. Young women's genital self-image and effects of exposure to pictures of natural vulvas. J Psychosom Obstet Gynaecol. 2017;38:249-55.

37. Spriggs M, Gillam L. Body dysmorphic disorder: contraindication or ethical justification for female genital cosmetic surgery in adolescents. Bioethics 2016; 30:706-13.

\section{AUTHOR CONTRIBUTIONS}

AK drafted and wrote the paper. LM drafted and proof read the paper.

\section{COMPETING INTERESTS}

The authors declare no competing interests.

\section{ADDITIONAL INFORMATION}

Correspondence and requests for materials should be addressed to Andreas Kalampalikis.

Reprints and permission information is available at http://www.nature.com/ reprints

Publisher's note Springer Nature remains neutral with regard to jurisdictional claims in published maps and institutional affiliations. 